\title{
Systemic and acute administration of parathyroid hormone-related peptide(1-36) stimulates endogenous beta cell proliferation while preserving function in adult mice
}

\author{
K. Williams • D. Abanquah • S. Joshi-Gokhale $\cdot$ A. Otero $\cdot$ H. Lin $\cdot$ N. K. Guthalu \\ X. Zhang • A. Mozar • A. Bisello • A. F. Stewart • A. Garcia-Ocaña • R. C. Vasavada
}

Received: 22 April 2011 / Accepted: 3 June 2011 /Published online: 29 July 2011

(C) Springer-Verlag 2011

\begin{abstract}
Aims/hypothesis A major focus in the treatment of diabetes is to identify factors that stimulate endogenous beta cell growth while preserving function. The first 36 amino acids of parathyroid hormone-related protein (PTHrP) are sufficient to enhance proliferation and function in rodent and human beta cells in vitro. This study examined whether acute and systemic administration of the amino-terminal PTHrP(1-36) peptide can achieve similar effects in rodent beta cells in vivo. Methods Adult male mice were injected with 40, 80 or $160 \mu \mathrm{g}$ of PTHrP(1-36) per $\mathrm{kg}$ body weight or with vehicle for 25 days. Glucose and beta cell homeostasis, as well as expression of differentiation markers and cell cycle genes were analysed.

Results All three doses of PTHrP(1-36) significantly enhanced beta cell proliferation in vivo at day 25 , with $160 \mu \mathrm{g} /$ $\mathrm{kg}$ PTHrP(1-36) increasing proliferation as early as day 5. Importantly, the two higher doses of PTHrP(1-36) caused a significant $30 \%$ expansion of beta cell mass, with a short-term improvement in glucose tolerance. PTHrP(1-36) did not cause hypercalcaemia, or change islet number, beta cell size, beta cell death or expression of differentiation markers. Analysis of islet G1/S cell cycle proteins revealed that chronic overabundance of PTHrP(1-139) in the beta cell significantly increased the cell cycle activator cyclin D2 and decreased levels of cyclin-
\end{abstract}

Electronic supplementary material The online version of this article (doi:10.1007/s00125-011-2260-z) contains peer-reviewed but unedited supplementary material, which is available to authorised users.

K. Williams $\cdot$ D. Abanquah $\cdot$ S. Joshi-Gokhale $\cdot$ A. Otero $\cdot$

H. Lin $\cdot$ N. K. Guthalu $\cdot$ X. Zhang $\cdot$ A. Mozar $\cdot$ A. Bisello •

A. F. Stewart $\cdot$ A. Garcia-Ocaña $\cdot$ R. C. Vasavada $(\bowtie)$

Division of Endocrinology, University of Pittsburgh,

200 Lothrop St, BST-E1157,

Pittsburgh, PA 15261, USA

e-mail: vasavada@pitt.edu dependent kinase 4 inhibitor (p16 ${ }^{\operatorname{Ink} 4 a}[\operatorname{Ink} 4 a$ also known as Cdkn2a]), but acute treatment with PTHrP(1-36) did not.

Conclusions/interpretation Acute and systemic administration of PTHrP(1-36) increases rodent beta cell proliferation and mass without negatively affecting function or survival. These findings highlight the future potential therapeutic effectiveness of this peptide under diabetes-related pathophysiological conditions.

Keywords Amino-terminal parathyroid hormone-related protein - Beta cell proliferation - Cyclin D2 - In vivo . $\mathrm{p} 16^{I N K 4 a}$

$\begin{array}{ll}\text { Abbreviations } \\ \text { GLP-1 } & \text { Glucagon-like polypeptide-1 } \\ \text { INK } & \text { Inhibitor of kinase } \\ \text { IPGTT } & \text { Intraperitoneal glucose tolerance test } \\ \text { Maf } & \text { v-Maf musculoaponeurotic fibrosarcoma } \\ & \text { oncogene family } \\ \text { p16 } & \text { Cyclin-dependent kinase } 4 \text { inhibitor } \\ \text { P-40 } & \text { Peptide at } 40 \mu \mathrm{g} / \mathrm{kg} \text { body weight } \\ \text { P-80 } & \text { Peptide at } 80 \mu \mathrm{g} / \mathrm{kg} \text { body weight } \\ \text { P-160 } & \text { Peptide at } 160 \mu \mathrm{g} / \mathrm{kg} \text { body weight } \\ \text { PCNA } & \text { Proliferating cell nuclear antigen } \\ \text { PKC } & \text { Protein kinase C } \\ \text { PTH } & \text { Parathyroid hormone } \\ \text { PTHR1 } & \text { PTH receptor-1 } \\ \text { PTHrP } & \text { Parathyroid hormone-related protein } \\ \text { RIP } & \text { Rat insulin promoter }\end{array}$

\section{Introduction}

Diabetes results from a loss of functional beta cells. Therefore a major goal in the treatment of diabetes is to 
find ways to induce endogenous beta cell regeneration without negatively affecting beta cell function. Proliferation is an important mechanism for normal postnatal growth and for regeneration after specific injury in rodent beta cells [13]. Importantly, beta cell proliferation has also been documented in humans, albeit less frequently $[4,5]$, providing a rational basis to search for molecules that can acutely enhance pancreatic beta cell replication and/or function in vivo. We examined the potential of parathyroid hormone (PTH)-related protein (PTHrP) in this context.

PTHrP is a 139 (rodent) or 173 (human) amino acid protein, which was first discovered as a tumour peptide that causes humoral hypercalcaemia of malignancy. It has since been shown to be produced in every tissue in the body, both during development and in adult life. Its receptor, the Gprotein-coupled seven transmembrane PTH receptor-1 (PTHR1), which recognises the amino-terminal regions of PTHrP and its related member PTH, is also produced in the same or adjacent cells as PTHrP [6]. PTHrP/PTHR1 signalling is critical for the development and differentiation of numerous tissues, and for the sustenance of life itself, as mutations in this pathway lead to embryonic/neonatal death in rodents and humans [6-9].

PTHrP is a promising candidate for the promotion of endogenous beta cell proliferation for several reasons. PTHrP and its receptor, PTHR1, are both normally produced in rodent and human beta cells [10-14]. Indeed, several studies have now shown that PTHrP can enhance beta cell function and proliferation in vitro in human and rodent beta cells [13-17]. Of particular relevance is the finding that the first 36 amino acids of PTHrP are sufficient to manifest its salutary effects on beta cell proliferation and function in vitro [13-17]. Furthermore, we have found that full-length PTHrP also enhances beta cell growth and function in vivo, when produced under the rat insulin promoter (RIP) in transgenic mice [12, 15, 18, 19]. RIPPTHrP (also known as Pthlh) transgenic mice are hypoglycaemic and hyperinsulinaemic, and have improved glucose tolerance, increased beta cell proliferation and enhanced beta cell mass. Finally, $\operatorname{PTHrP}(1-36)$ peptide is currently being used for its anabolic effects on bone in human clinical studies, demonstrating its probable safety as a potential therapeutic agent $[20,21]$.

Based on these studies, we hypothesised that PTHrP(136) has the potential to enhance endogenous beta cell proliferation and/or function in vivo, when administered acutely in mice. Indeed, as demonstrated here, PTHrP(136) augmented beta cell proliferation as early as the 5th day of treatment, continuing to do so until day 25 . This resulted in a significant $30 \%$ increase in beta cell mass with the two higher doses of PTHrP(1-36), without negatively affecting plasma glucose levels or beta cell differentiation, size and turnover. Although PTHrP(1-36) significantly improved glucose tolerance at the beginning, glucose tolerance returned completely to baseline levels by the end of the treatment, suggesting a potential desensitisation of the functional effect of PTHrP as the treatment progresses. Analysis of the cell cycle molecules regulated by PTHrP showed a significant increase in abundance of the activator cyclin D2 and a decrease in the cyclin-dependent kinase 4 inhibitor (p16 ${ }^{\operatorname{Ink} 4 a}$ [Ink4a also known as Cdkn2a]), in transgenic mouse islets overproducing PTHrP(1-139) in the beta cell; this did not occur in the islets of mice treated acutely and systemically with PTHrP(1-36). Thus, systemic administration of $\mathrm{PTHrP}(1-36)$ peptide can acutely induce beta cell replication and mass with short-term improvement in glucose tolerance in normal adult mice, identifying this peptide as a potential agent for beta cell regeneration.

\section{Methods}

Experimental design Balb/C male mice were injected s.c. with $\mathrm{PTHrP}(1-36)$ peptide at 40 (P-40 mice), 80 (P-80 mice) or 160 (P-160 mice) $\mu \mathrm{g} / \mathrm{kg}$ body weight or vehicle (control). Injections were once daily for 5 days per week for 25 days, after which pancreases or islets were removed. PTHrP(1-36) was synthesised and assayed for activity as described previously [20, 21]. RIP-PTHrP transgenic mice bred on to a CD1 background were generated as described previously [18]. All studies were performed with the approval of, and in accordance with, guidelines established by the University of Pittsburgh Institutional Animal Care and Use Committee. For further details on experimental design, see electronic supplementary material (ESM) Methods.

Glucose homeostasis and islet isolation Blood glucose was measured 5 days per week for 25 days using a portable glucometer (Medisense, Bedford, MA, USA). An intraperitoneal glucose tolerance test (IPGTT) was performed on days 9 and 23 in mice that had been fasted for 16 to $18 \mathrm{~h}$. These mice were injected i.p. with $2 \mathrm{~g}$ glucose per $\mathrm{kg}$ body weight $[12,15]$. Islets that had been isolated for gene expression analysis from control and P-160 mice at day 5 or 25, and from 3- to 6-monthold RIP-PTHrP transgenic and normal mice were immediately handpicked in RPMI medium with $5.5 \mathrm{mmol} / \mathrm{l}$ glucose and $1 \%$ (vol./vol.) FBS [15].

Plasma calcium Plasma was obtained from retro-orbital bleeds on days 8 and 25, and plasma calcium measured using a blood gas analyser (Rapid Lab 348; Bayer, Leverkusen, Germany).

Pancreatic histomorphometry and beta cell homeostasis Histomorphometric analysis was performed on two to 
three insulin-stained pancreatic sections per animal to quantify the number of islets or ratio of beta cell area to pancreatic area using the Image J program (NIH) [15]. Beta cell size, death and proliferation were quantified respectively as: (1) insulin-positive area per total number of insulin-positive cells ( $728 \pm 36$ beta cells/mouse); (2) percentage of condensed beta cell nuclei after co-staining for insulin and propidium iodide [12], or TUNEL (Promega, Madison, WI, USA) $(1,043 \pm 79$ or $1,298 \pm 174$ beta cells/ mouse); and (3) percentage of BrdU-positive (Amersham Pharmacia Biotech, Piscataway, NJ, USA) or proliferating cell nuclear antigen (PCNA)-positive (Santa Cruz Biotechnology, Santa Cruz, CA, USA) beta cells $(1,538 \pm 54$ beta cells/mouse). Details on above, see also ESM Methods

RNA and protein analysis RNA from islets of control and P160 mice at day 25 , or of 3- to 6-month-old RIP-PTHrP transgenic and normal mice was processed and analysed on a real-time PCR system (ABI 7300; Life Technologies, Carlsbad, CA, USA). Whole-islet extracts were analysed by immunoblot and quantitative densitometry was performed using the Image J program [15]. Primers, primary antibodies and additional details are in ESM Table 1 and ESM Methods.

Statistical analysis Data are expressed as the mean \pm SE. Statistical significance, considered to be given at $p \leq 0.05$, was determined by unpaired two-tailed Student's $t$ test or a one-way ANOVA with Dunnett's post hoc test.

\section{Results}

Effect of PTHrP(1-36) administration on body weight and plasma calcium $\mathrm{PTHrP}(1-36)$ was systemically adminis- tered by s.c. injection in 8 -week-old male Balb/C mice at three different doses, 40, 80 and $160 \mu \mathrm{g} / \mathrm{kg}$ body weight or vehicle as control, for 5 days per week for 25 days (Fig. 1a). Body weight, plasma calcium, glucose and IPGTT, as well as beta cell proliferation, mass, size and death were analysed at specific times during the treatment (Fig. 1a). There was no change in the average body weight of the PTHrP(1-36)-injected mice, P-40, P-80 and P-160, compared with controls during the 25 days of treatment (Fig. 1b). As PTHrP has been discovered to be a factor that causes humoral hypercalcaemia of malignancy, we measured plasma calcium levels in these mice at early (day 8) and late (day 25) time points, and saw no significant increase in the average plasma calcium level, even at the highest dose of PTHrP(1-36) used (Fig. 1c).

PTHrP(1-36) increased beta cell mass without affecting islet number, beta cell size or beta cell death After 25 days of treatment, beta cell mass was measured in insulin-stained pancreatic sections from all four groups of mice. There were no significant changes in the pancreatic weights of these mice (Fig. 2a). PTHrP(1-36) caused a significant $29 \%$ increase in beta cell mass at the 80 and $160 \mu \mathrm{g} / \mathrm{kg}$ doses, but not at the $40 \mu \mathrm{g} / \mathrm{kg}$ dose relative to controls (Fig. 2b).

We then determined whether the increase in beta cell mass with $\mathrm{PTHrP}(1-36)$ resulted from changes in islet number, beta cell size or beta cell turnover. $\mathrm{PTHrP}(1-36)$ did not significantly change the total number of islets per pancreatic area (Fig. 3a) or the number of singlet and doublet insulin-positive cells in the exocrine tissue and ducts of the pancreases, which are presumed to represent newly formed islets (Fig. 3b). Beta cell hypertrophy did not contribute to the PTHrP(1-36)-induced increase in beta cell mass, as beta cell size was not significantly changed in any a

s.c. $\mathrm{PTHrP}(1-36) /$ vehicle; body weight; glucose; (5 days/week)

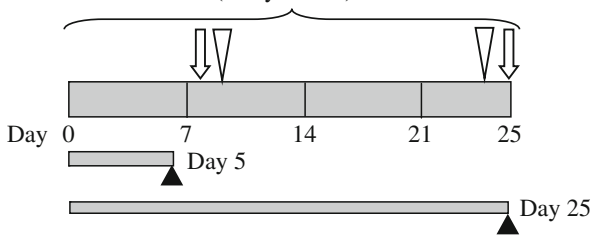

b

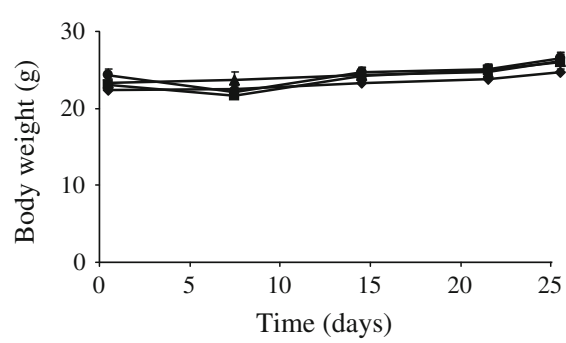

c

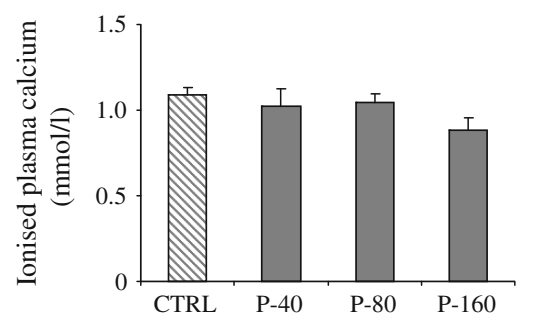

Fig. 1 Effect of systemic administration of PTHrP(1-36) on body weight and plasma calcium. a Schematic representation of the experimental design used in $\mathrm{Balb} / \mathrm{C}$ male mice. The top grey bar represents the duration of the experiment (25 days). Mice were weighed, injected s.c. with vehicle or three different doses of PTHrP (1-36), and blood glucose was measured 5 days/week for the duration of the experiment. The white arrows mark days 8 and 25 when plasma calcium was measured. White triangles mark days 9 and 23 when IPGTT was done. The black triangles (days 5 and 25) represent administration of BrdU and killing of mice for removal of pancreases or islets. b Average body weight in the four groups of mice receiving vehicle (controls, diamonds), or $\operatorname{PTHrP}(1-36)$ at 40 (triangles), 80 (squares) or 160 (circles) $\mu \mathrm{g} / \mathrm{kg}$ body weight over the 25-day period; $n=6-7$ mice/group. c Average plasma calcium levels measured at days 8 and 25 in the four groups of mice receiving vehicle (CTRL), or PTHrP(1-36) at $40(\mathrm{P}-40), 80(\mathrm{P}-80)$ or 160 $(\mathrm{P}-160) \mu \mathrm{g} / \mathrm{kg}$ body weight; $n=4$ mice/group 
a

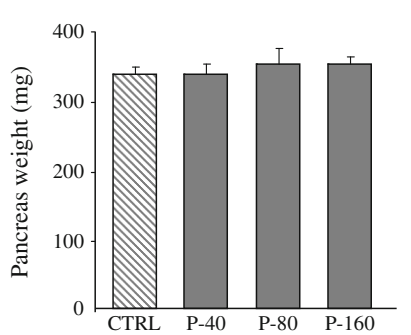

b

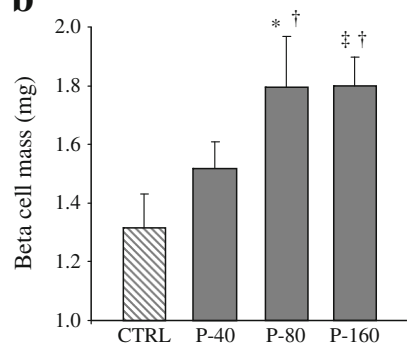

Fig. 2 Systemic administration of $\operatorname{PTHrP}(1-36)$ increases beta cell mass. a Pancreatic weight and (b) quantification of beta cell mass in insulin-stained pancreatic sections from control (CTRL) $(n=9)$, P-40 $(n=6), \mathrm{P}-80(n=6)$ and P-160 $(n=8)$ mice after 25 days of treatment. ${ }^{*} p<0.05$ and ${ }^{\ddagger} p<0.007$ vs control by Student's $t$ test; ${ }^{\dagger} p<0.05$ vs control by one-way ANOVA

of the PTHrP(1-36)-treated groups vs controls (Fig. 3c). Finally, we measured beta cell death using two different methods: co-staining for insulin and propidium iodide (Fig. 3d), or TUNEL. The percentage of condensed beta cell nuclei, representing cell death, was similar in the four groups of mice (Fig. 3e), as was the percentage of TUNELpositive beta cells in control and P-160 mice (Fig. 3f). This suggests that PTHrP(1-36) does not affect beta cell turnover under basal conditions.

All three doses of PTHrP(1-36) enhanced beta cell proliferation To determine whether changes in beta cell

proliferation contributed to the PTHrP(1-36)-mediated increase in beta cell mass, the percentage of BrdUpositive beta cell nuclei was quantified after 25 days of PTHrP(1-36) treatment. There was a significant 1.7-fold to twofold increase in beta cell proliferation with all three doses of PTHrP(1-36) relative to controls (Fig. 4a). This was also confirmed using a different method to measure beta cell proliferation, namely co-staining with PCNA and insulin, which also showed a 1.6-fold increase in P-80 vs control mice (Fig. 4b).

PTHrP(1-36) stimulates beta cell proliferation after only 5 days of treatment To determine whether a progressive increase in beta cell proliferation could be responsible for the increase in beta cell mass, we measured beta cell replication at an earlier time point in $\mathrm{P}-160$ mice. Mice injected with vehicle or $160 \mu \mathrm{g} \operatorname{PTHrP}(1-36)$ were analysed for beta cell proliferation at day 5 , either after a single dose of BrdU injected $6 \mathrm{~h}$ prior to removal of the pancreases (Fig. 5a, b), or after giving BrdU in the drinking water for the previous 5 days (Fig. 5c, d). The two different methods of BrdU treatment provide information about beta cell replication occurring on day 5 vs cumulative proliferation over 5 days respectively. Using the single-dose BrdU injection approach, the percentage of BrdU-positive beta cells was significantly increased by about twofold in P-160 mice compared with controls (Fig. 5a, b, e), indicating an
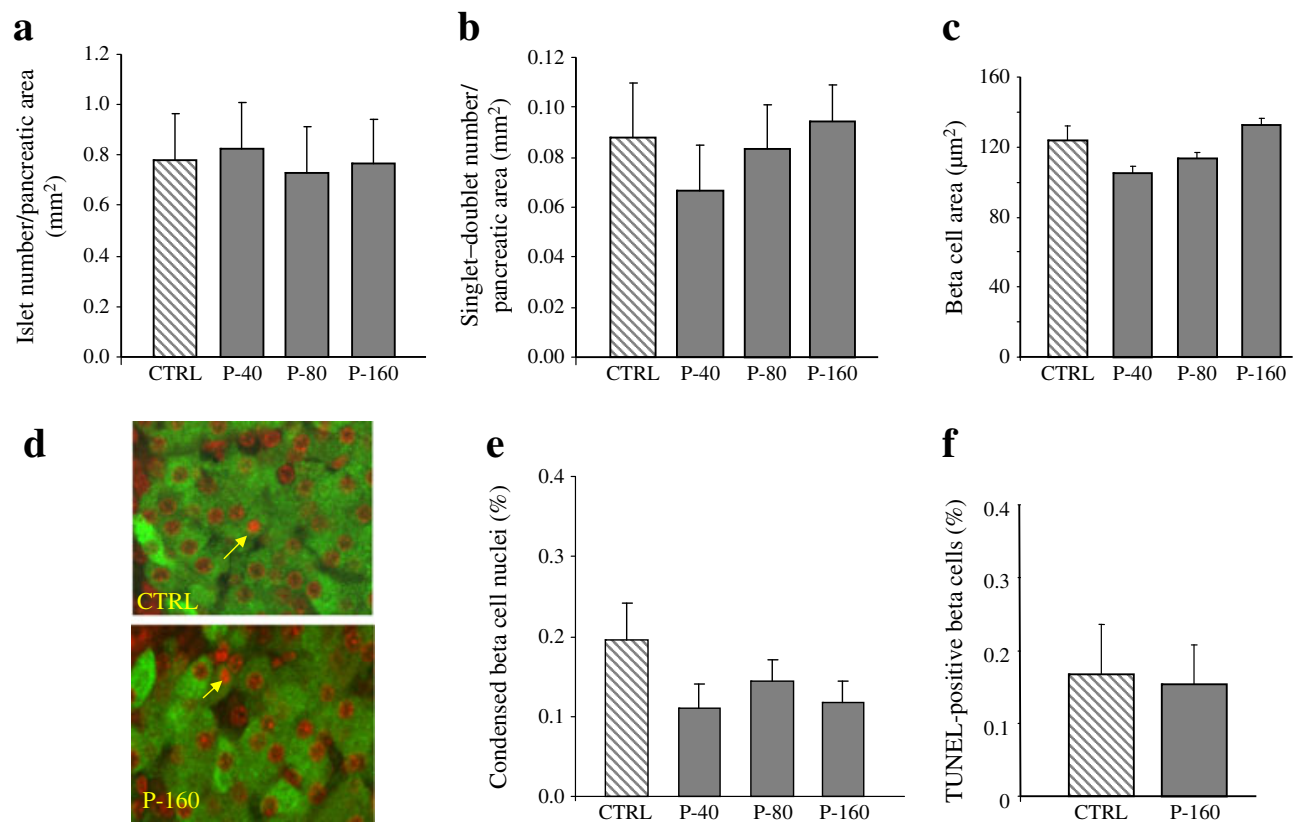

Fig. $3 \mathrm{PTHrP}(1-36)$ treatment does not cause a significant change in islet number, beta cell size or beta cell turnover. a Total number of islets/pancreatic area, (b) number of insulin-positive singlet or doublet cells/pancreatic area in the exocrine tissue or ducts of the pancreas, and (c) average beta cell area in control (CTRL), P-40, P-80 and P-160 mice; $n=4-5$ mice/group. d Pancreas sections from CTRL and
P-160 mice stained for insulin (green) and propidium iodide (red), with arrows identifying the infrequent condensed beta cell nuclei. e Quantification of the percentage of condensed beta cell nuclei in the four groups of mice; $n=6-7$ mice/group. $\mathbf{f}$ Quantification of the percentage of TUNEL-positive beta cell nuclei in control and P-160 mice; $n=4$ mice/group 

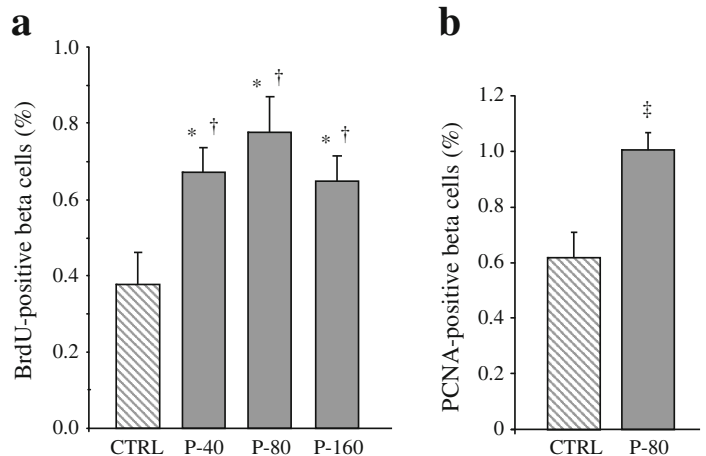

Fig. 4 PTHrP(1-36) stimulates beta cell proliferation after 25 days of treatment. Beta cell proliferation was measured at day 25 as (a) percentage of BrdU-positive beta cell nuclei in control (CTRL), P-40, P-80 and P-160 mice, and (b) as percentage of PCNA-positive beta cell nuclei in groups as shown; $n=6-7$ mice/group. ${ }^{*} p<0.05$ and ${ }^{\ddagger} p<0.02$ vs control by Student's $t$ test; ${ }^{\dagger} p \leq 0.05$ vs control by one-way ANOVA

induction of proliferation on day 5 by $\operatorname{PTHrP}(1-36)$. As expected, the cumulative proliferation over 5 days in control mice receiving BrdU in their drinking water was significantly greater than in the single-dose BrdU control mice (Fig. 5a, c, e). Here, too, the P-160 mice showed a significant twofold increase in proliferation compared with control mice in the group treated for 5 days with BrdU in their drinking water (Fig. $5 \mathrm{c}-\mathrm{e}$ ). The amount of water consumed by the control and $\mathrm{P}-160$ mice receiving BrdU in drinking water was similar (not shown). Finally, proliferation quantified by PCNA-positive beta cells was also significantly increased after 5 days of $\operatorname{PTHrP}(1-36)$ treatment in P-160 mice compared with controls (Fig. 5f).

\section{Effect of PTHrP(1-36) on glucose homeostasis and beta} cell differentiation Glucose homeostasis, evaluated as weekly random blood glucose (Fig. 6a) or fasting plasma glucose at days 9 and 23 (0 min time point in IPGTT experiments; Fig. 6b, d), did not differ significantly among the four groups of mice. However, glucose tolerance was significantly and dose-dependently improved at day 9 following treatment with PTHrP(1-36) in the P-80 and P160 groups vs controls (Fig. 6b, c). Surprisingly, the improvement in glucose tolerance observed at day 9 completely disappeared at day 23 in all three $\mathrm{PTHrP}(1-$ 36)-treated groups (Fig. 6d).

To determine whether PTHrP(1-36)-induced beta cell proliferation caused changes in expression of genes regulating the function or differentiation of the beta cell, we examined the transcriptional profile of these genes in islets isolated from control or P-160 mice at day 25. There was no significant change in expression of genes encoding islet hormones (insulin, somatostatin), glucose sensors (Glut2, glucokinase, Kir6.2) or transcription factors important for beta cell differentiation and function (pancreatic and duodenal ho-
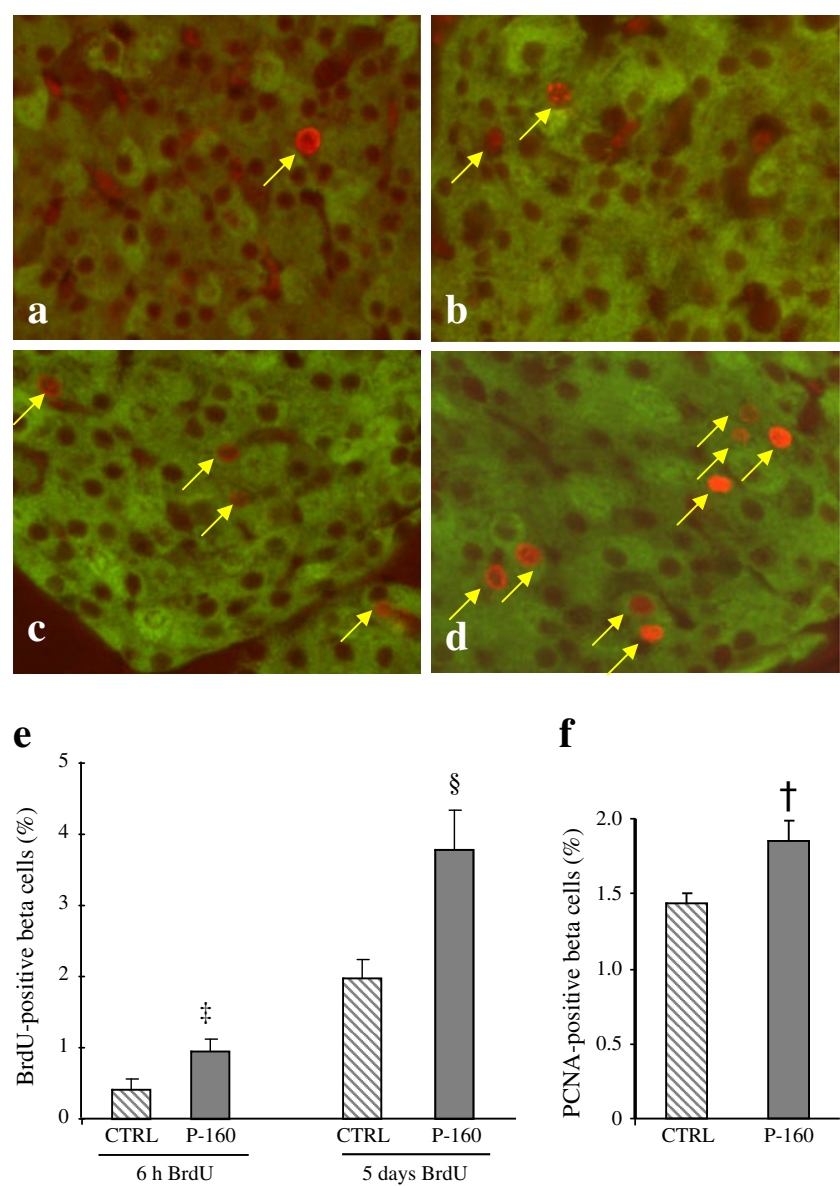

f

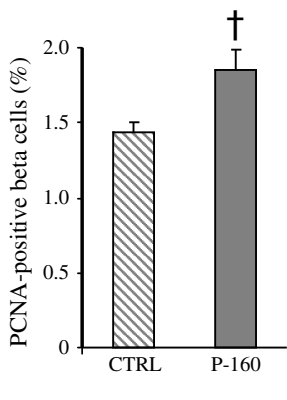

Fig. 5 PTHrP(1-36) stimulates beta cell proliferation by day 5 of treatment. The effect on beta cell proliferation was measured after 5 days of $160 \mu \mathrm{g} / \mathrm{kg}$ PTHrP(1-36) treatment. a-d Pancreatic sections stained for insulin (green) and BrdU (red), with BrdU-positive beta cells indicated by arrows. Sections were from control (a, c) and P-160 (b, d) mice injected with a single dose of $\operatorname{BrdU} 6 \mathrm{~h}(\mathbf{a}, \mathbf{b})$ or given BrdU in drinking water for 5 days $(\mathbf{c}, \mathbf{d})$ prior to killing. e Quantification of beta cell proliferation as percentage of BrdUpositive beta cells in control (CTRL) and P-160 mice given BrdU as indicated ( $n=3-4 \mathrm{mice} / g r o u p)$, and (f) as percentage of PCNApositive beta cells in mice as shown. As PCNA is an endogenous marker of proliferation, mice from the $6 \mathrm{~h}$ and 5 day groups were combined for this analysis; $n=7-8$ mice/group. ${ }^{\dagger} p<0.02,{ }^{\star} p<0.04$, $\S_{p}<0.008$ vs corresponding controls by Student's $t$ test

meobox 1 [Pdx1], v-maf musculoaponeurotic fibrosarcoma oncogene family [Maf], protein A [MafA], Maf protein B, neurogenic differentiation[Neurod], NK6 homeobox 1 [Nkx6.1]) (Fig. 6e). This suggests that the enhanced beta cell proliferation induced by $\operatorname{PTHrP}(1-36)$ treatment does not negatively affect beta cell function or differentiation.

PTHrP modulates expression of the G1/S cell cycle regulators, cyclin D2 and p16 ${ }^{\text {Ink4a }}$, in islets We next examined whether PTHrP regulates expression of the cell cycle molecules in the $\mathrm{G} 1 / \mathrm{S}$ phase. There was no significant change in mRNA expression of the genes encoding cyclins (cyclin D1 to D3, Al and E2), cyclin- 
Fig. 6 Effect of PTHrP(1-36) on glucose homeostasis and beta cell differentiation. a Weekly blood glucose, b IPGTT on day 9 and (c) AUC of the glucose response on day 9 showed a significant improvement in the response at the two higher doses, i.e. P-80 and P160 , of PTHrP(1-36); $n=6-17$ mice/group; ${ }^{*} p<0.05$ and $* * * p<$ 0.001 vs control (CTRL) by Student's $t$ test. d IPGTT on day 23 of treatment showed no difference between the four groups of mice; $n=6-7$ mice/group. a, $\mathbf{b}$, d Diamonds, control; triangles, P-40; squares, P-80; circles, P160. e Expression of differentiation markers by real-time PCR in islets from control (hatched bars) and P-160 (grey bars) mice after 25 days of treatment. PCR cycles for each gene were compared with actin as internal control; $n=$ 4 mice/group, samples done in duplicate. Som, also known as Sst; Glut2, also known as $S l c 2 a 2$; Kir6.2, also known as Kcnj11 $\mathbf{a}$
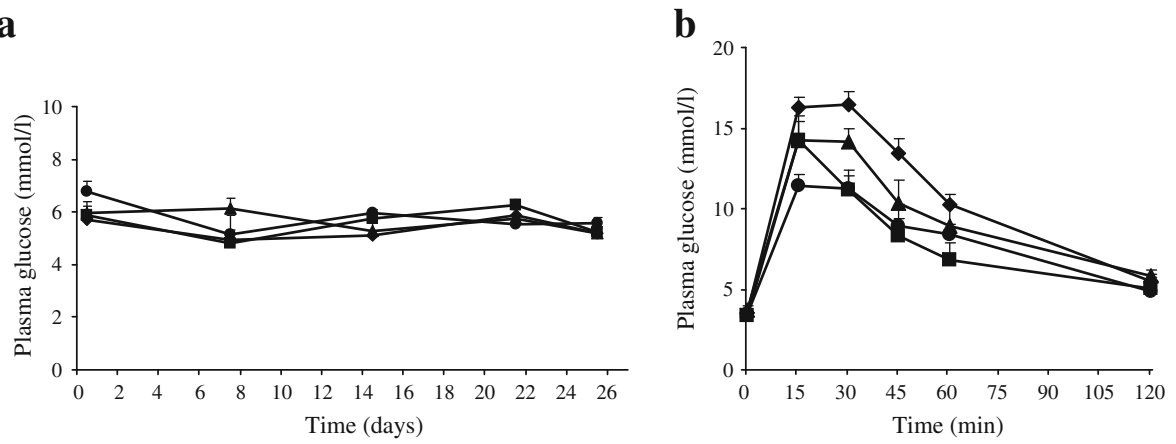

c

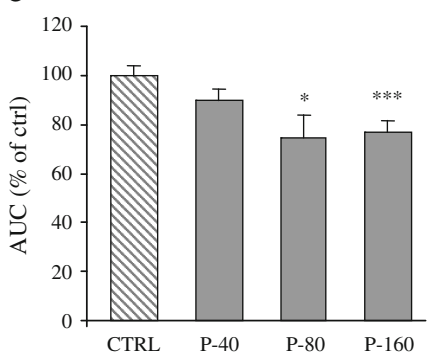

d

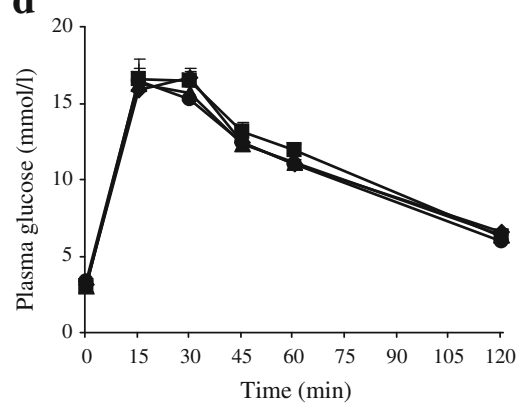

e

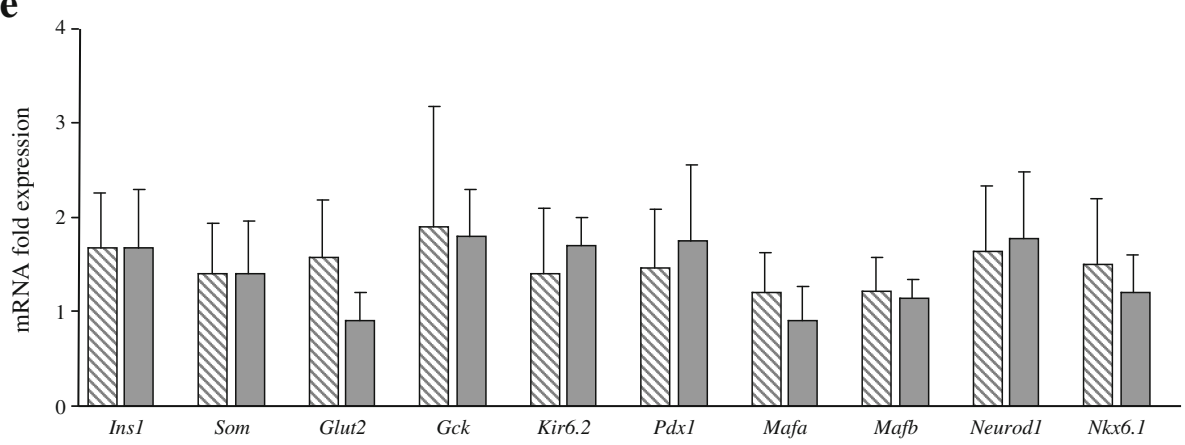

dependent kinases 2, 4 and 6 , or the inhibitors $p 21^{\text {Cip } 1}$ (Cipl also known as Cdkn1a) and p27 ${ }^{\text {Kipl }}$ (Kipl also known as $C d k n 1 b)$ in islets of P-160 mice relative to controls after 25 days of treatment (Fig. 7a). To determine whether PTHrP regulates these molecules at the protein level, we performed western blot analysis on islet extracts. Since this approach requires a much larger number of islets, we used islets from RIP-PTHrP transgenic mice and normal littermates, as the supply of these islets was abundant relative to islets from the $\mathrm{PTHrP}(1-36)$-injected mice and the PTHrP(1-139) produced in the islets of RIP$P T H r P$ transgenic mice also induces beta cell proliferation [15]. There was no change in abundance of the G1/S cell cycle activators cyclin D1, D3 and E, or of cyclindependent kinases 2 and 4 , or of the inhibitors, $\mathrm{p} 18^{\text {Ink } 4 c}$

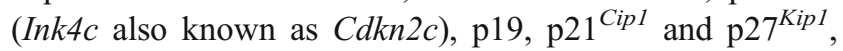
and $\mathrm{p} 57^{\text {Kip } 2}$ (Kip2 also known as Cdkn1c) in transgenic vs normal mouse islets (Fig. 7b). In contrast, the G1/S cell cycle activator cyclin D2 (Fig. 7b, c) was significantly upregulated and the inhibitor p16 ${ }^{\text {Ink4a }}$ (Fig. 7b, d) was significantly downregulated, both by approximately twofold in islets of RIP-PTHrP transgenic vs normal mice. To determine whether acute $\operatorname{PTHrP}(1-36)$ treatment led to similar changes in abundance, islets were isolated from control and P-160 mice after 5 days of treatment, when a significant increase in beta cell proliferation was observed in P-160 mice (Fig. 5). Analysis of cyclin D2 (Fig. 7e) and p16 ${ }^{\text {Ink } 4 a}$ (Fig. 7f) proteins showed no significant difference in expression between control and P-160 mice, suggesting that PTHrP(1-139) overproduction and PTHrP(1-36) administration enhance beta cell replication by different mechanisms.

\section{Discussion}

This study demonstrates that acute and systemic administration of amino-terminal $\mathrm{PTHrP}(1-36)$ peptide in rodents can stimulate beta cell proliferation and enhance beta cell mass in vivo, without negatively affecting beta cell function 


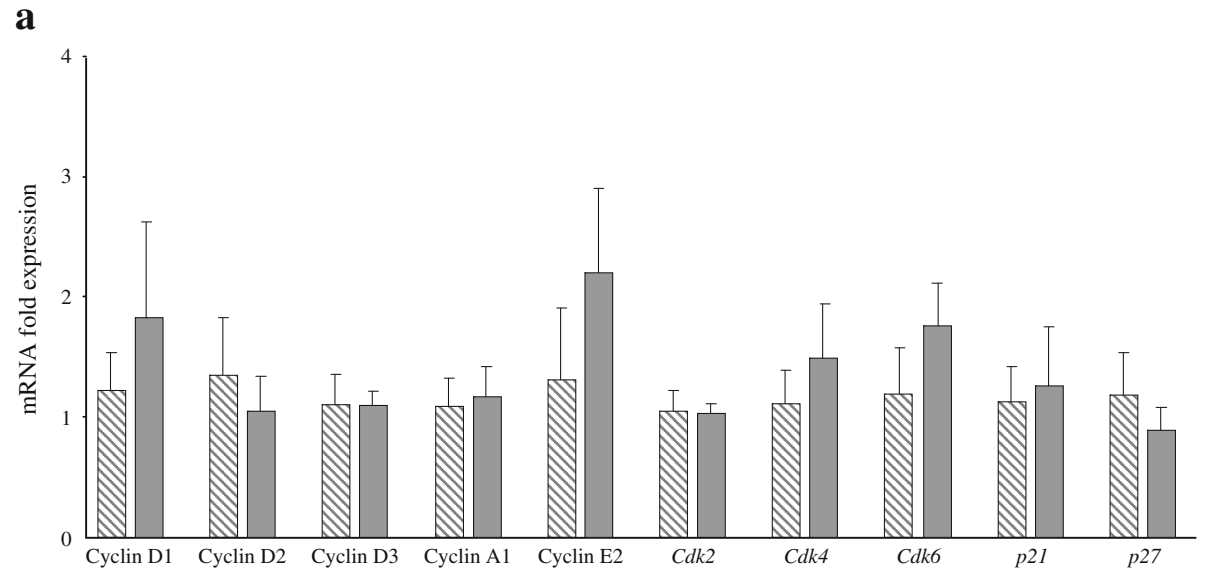

b

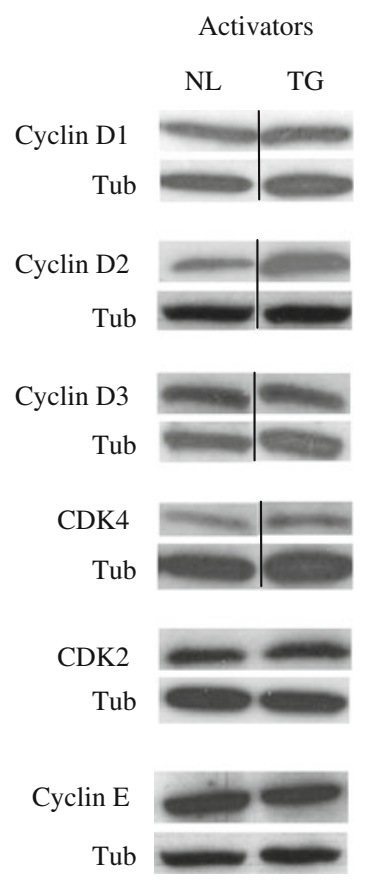

c

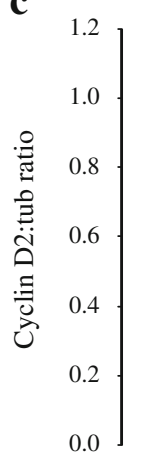

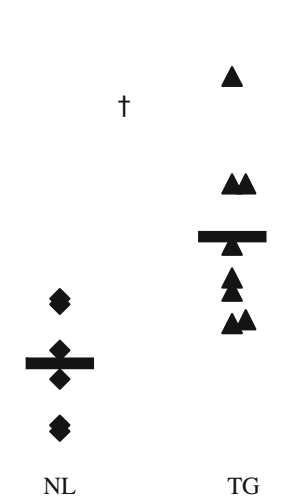

e
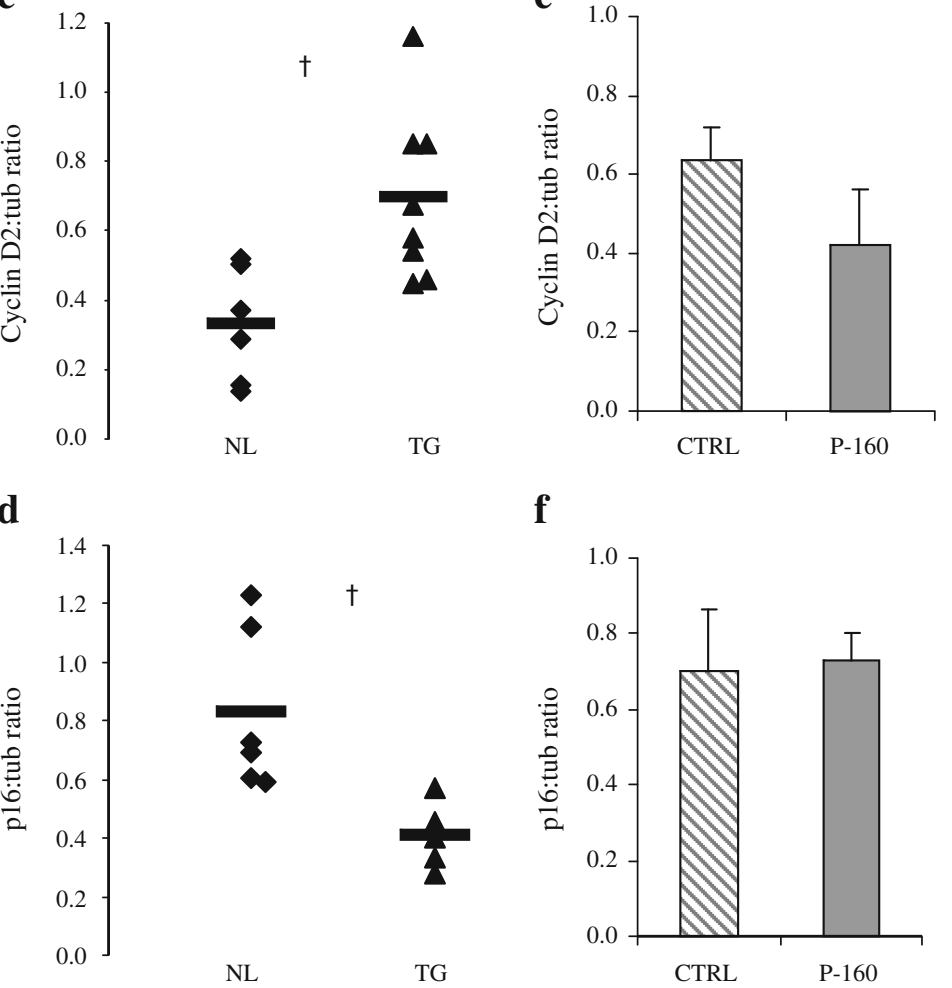

f

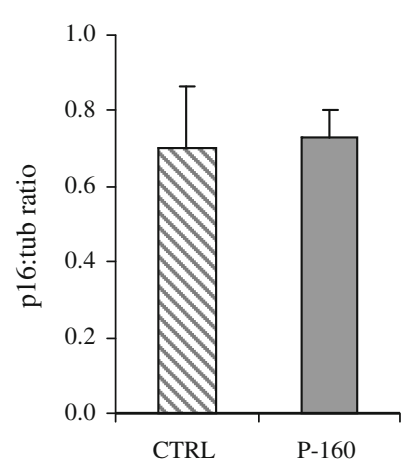

Fig. 7 The G1/S cell cycle activator, cyclin D2, is upregulated and the inhibitor, $\mathrm{p} 16^{\text {Ink4a }}$, is downregulated in RIP-PTHrP transgenic, but not in P-160 islets. a Expression of G1/S cell cycle regulators by real-time PCR in islets from control (hatched bars) and P-160 (grey bars) mice after 25 days of treatment. PCR cycles for each gene were compared with actin as an internal control; $n=3-4$ mice/group, with samples evaluated in duplicate. b Representative western blot analysis of the G1/S cell cycle activators and inhibitors in islets isolated from RIPPTHrP transgenic (TG) and normal (NL) mice using tubulin (Tub) as internal control. Vertical lines divide samples from different regions on the same gel. CDK2/4, cyclin-dependent kinase 2/4. c Quantification

or survival. Previous studies have shown that transgenic production of the full-length $\mathrm{PTHrP}(1-139)$ in beta cells of RIP-PTHrP transgenic mice results in an increase in beta cell mass, proliferation and islet number, and in improved of the ratio of cyclin D2: tubulin and (d) $\mathrm{p} 16^{\text {Ink4a }}$ : tubulin protein showing the individual ratios from each islet sample. The horizontal line depicts the mean. Of all the cell cycle proteins analysed (b) $(n=5-$ 9 islet preparations/group), only cyclin D2 was significantly more abundant and p16 $6^{\text {Ink4a }}$ significantly less abundant in RIP-PTHrP transgenic islets compared with normal islets; ${ }^{\dagger} p<0.02$. e Quantification of the ratio of cyclin D2 : tubulin and (f) $\mathrm{p} 16^{\operatorname{Ink} 4 a}$ : tubulin protein in islets isolated from control (CTRL) and P-160 mice after 5 days of treatment showed no difference in abundance of these proteins; $n=5-6$ islet preparations/group

glucose homeostasis in these mice $[12,15,18,19]$. In addition, in vitro studies have shown that the amino-terminal PTHrP(1-36) peptide is sufficient to enhance not only proliferation, in rodent insulinoma cell lines and primary 
human beta cells, but also function, increasing insulin mRNA and protein, and augmenting glucose-stimulated insulin secretion [13-17]. Based on these data, we examined whether PTHrP(1-36) peptide could induce similar effects in vivo, as a first step towards determining its therapeutic potential for the treatment of diabetes.

The major novel aspects of this study compared with previous in vivo studies using RIP-PTHrP transgenic mice are: (1) PTHrP is administered systemically rather than being expressed endogenously in the beta cell; (2) PTHrP treatment is acute, for a short time, rather than via continuous expression in the beta cell; (3) PTHrP is given to adult mice rather than being produced from conception of the beta cell in transgenic mice; and (4) only the aminoterminal PTHrP(1-36) peptide is being administered, rather than the entire $\mathrm{PTHrP}(1-139)$ protein being produced in transgenic mice.

Our choice of doses and duration of PTHrP(1-36) treatment was based on previous work showing that amino-terminal PTHrP and PTH have anabolic effects on bone using a similar treatment regimen [22, 23]. Indeed, we found that systemic administration of all three PTHrP(136) doses increased endogenous beta cell proliferation at 4 weeks, as well as in the early phase of treatment for the highest $160 \mu \mathrm{g} / \mathrm{kg}$ dose. Importantly, the two higher doses of PTHrP(1-36) caused a significant increase in beta cell mass. RIP-PTHrP transgenic mice exhibit a progressive increase in their beta cell mass, with no significant change at 1 week, and a significant twofold increase by 2 to 3 months, which further increases to threefold at 1 year [19]. It is therefore likely that prolonged systemic administration of PTHrP(1-36) beyond 1 month could result in a similar progressive increase in beta cell mass, an issue that will be addressed in future studies. The enhanced beta cell mass in the PTHrP(1-36)-treated mice is likely to have been due to the increase in beta cell replication and not to changes in beta cell size, turnover or islet number, as none of these variables changed significantly in these mice. This was somewhat different from our observations in RIP-PTHrP transgenic mice, which showed a significant twofold increase in islet number at 2 months of age [18, 19]. This difference could stem from the fact that in the transgenic mice, PTHrP is probably produced early in embryonic life when the insulin promoter is first activated in the beta cell and, being a secretory protein, could potentially influence differentiation of neighbouring progenitor cells. In the current study, PTHrP(1-36) was injected once a day into adult mice and is therefore less likely to have had effects on islet development or number.

Although some studies have shown that PTHrP stimulates beta cell proliferation $[13,15,16]$, very little is known about the effect of PTHrP on regulation of the G1/S cell cycle molecules at the transcriptional and protein levels in rodent islets. We found a significant increase in cyclin D2 protein and a decrease in the inhibitor $\mathrm{p} 16^{\text {Ink4a }}$ protein, in islets from RIP-PTHrP transgenic mice with overproduction of PTHrP(1-139) in beta cells vs normal littermates. PTHrP has been shown to modulate a number of cell cycle molecules. Thus it inhibits production of the cyclindependent kinase-interacting protein/kinase-inhibitory protein and inhibitor of kinase (INK) family of cell cycle inhibitors that includes $\mathrm{p} 15^{\operatorname{Ink} 4 b}$ (Ink4b also known as Cdkn2b), p $27^{\text {Kipl } 1}$ and $\mathrm{p} 57^{\text {Kip } 2}$, as well as inducing transcription of cyclin D1 in different cell types in which it enhances proliferation, including chondrocytes, early osteoblastic cells and vascular smooth muscle cells [2428]. Surprisingly, the increase in cyclin D2 and decrease in p16 ${ }^{\text {Ink } 4 a}$ abundance were not observed in islets isolated from P-160 mice after 5 days of PTHrP(1-36) treatment relative to control mice. This differential regulation of the cell cycle molecules in PTHrP(1-139) transgenic vs PTHrP (1-36)-treated islets could be the result of several factors including the following: (1) the effect of chronic PTHrP production vs acute treatment; (2) the effect of full-length PTHrP(1-139) and/or other PTHrP fragments vs only the amino-terminal PTHrP(1-36) peptide; (3) the effect of endogenous production vs exogenous treatment; and (4) possible local variations in effective concentrations of the protein. A recent report that is relevant to our findings found that mice lacking the nuclear localisation sequence and C-terminus of PTHrP (amino acids 85-139), but producing the amino-terminus PTHrP peptide showed decreased levels of cyclin D and increased levels of p16 $6^{\text {Ink4a }}$ in bone cells and embryonic fibroblasts [29], implying that the C-terminus region of PTHrP is required for the regulation of these cell cycle molecules. We observed the mirror effect of this in beta cells overproducing full-length PTHrP in vivo, but not in islets treated with only the amino-terminal $\mathrm{PTHrP}(1-36)$ peptide, again suggesting that the $\mathrm{C}$-terminus region of PTHrP is important in the regulation of cyclin D2 and $\mathrm{p} 16^{\text {Ink4a }}$. The question of whether the proliferative effects of PTHrP on rodent beta cells are mediated through the observed increase in cyclin D2 and/or decrease in $\mathrm{p} 16^{\text {Ink4a }}$ needs further verification.

RIP-PTHrP transgenic mice display hypoglycaemia and hyperinsulinaemia under fasting and non-fasting conditions, as well as improved glucose tolerance $[15,18,19]$. Systemic and acute administration of $\operatorname{PTHrP}(1-36)$ for 25 days did not alter plasma glucose in this study. However, there was a differential effect on glucose tolerance in the PTHrP-treated mice during the early vs the late phase of treatment. The significant improvement in glucose tolerance seen with the two higher doses of PTHrP(1-36) at day 9 was not observed at day 23 , despite a $30 \%$ increase in 
beta cell mass in the P- 80 and P-160 mice. The return of glucose tolerance to baseline values in these mice at day 23 is unlikely to be due to a negative impact of $\operatorname{PTHrP}(1-36)$ on beta cell function, as several studies have shown that PTHrP(1-36) increases insulin expression and enhances insulin secretion in rodent and human beta cells, similarly to full-length PTHrP [13, 15-17]. Thus, the short-term improvement in IPGTT vs the long-lasting effect on proliferation is more likely to be due to a signal-specific differential desensitisation/downregulation of the PTHR1. PTHrP is known to enhance beta cell function and proliferation through two distinct signalling pathways, namely activation of cyclic AMP with inhibition of the cJun N-terminal kinase pathway [17], and activation of the phosphatidylinositol 3-kinase and atypical protein kinase $\mathrm{C}$ (PKC) $\zeta$ pathway [15] respectively. In this context, there is evidence in osteoblasts that the desensitisation of PTHR1 is signalling pathway-specific, with a more pronounced effect on the cAMP/protein kinase-A pathway than on the phospholipase-C/PKC pathway [30]. Similarly, it is possible that the beta cell also displays preferential attenuation of the cAMP, but not of the atypical $\mathrm{PKC} \zeta$ signalling pathway downstream of the PTHR1, leading to more short-lived effects of PTHrP(1-36) on glucose homeostasis vs beta cell proliferation. Importantly, there was no overall negative impact of PTHrP(1-36) treatment on glucose homeostasis in these mice.

The current studies raise numerous interesting questions. What would be the effect of higher doses of PTHrP(1-36) injected for varying durations on glucose and beta cell homeostasis? What would be the effect of treating mice with PTH instead of PTHrP, or with mutant peptides that activate specific signalling pathways [31]? It seems plausible that increasing the dose and/or duration of $\operatorname{PTHrP}(1-36)$ treatment would be likely to further enhance beta cell growth, based on the progressive increase in beta cell mass observed with age in RIP-PTHrP transgenic mice [19]. However, it is possible that long-term treatment (for 3-6 months) with PTHrP(1-36) injected on a daily basis may not induce any further increase in beta cell mass, similarly to its effects in bone, where intermittent treatment is anabolic, but continuous or longer term treatment is catabolic or does not cause further increases in bone mass [22, 32]. Based on this, it may be more beneficial to treat mice less frequently (1-2 times per week) on a long-term basis to induce further increases in beta cell mass and perhaps improve glucose tolerance.

Another question is whether long-term systemic PTHrP (1-36) treatment could cause tumours or hypercalcaemia in mice? The doses of PTHrP(1-36) in this study did not cause hypercalcaemia over 25 days, nor did daily injections of PTHrP(1-36) in rats for 6 months [33] or overabundance of PTHrP in the beta cells of RIP-PTHrP transgenic mice [19]. Furthermore, we have not detected insulinomas in
RIP-PTHrP mice even after life-long ( $\sim 2$ years) production of PTHrP in their beta cells (R. C. Vasavada, unpublished observations). However, treatment duration and dose of the related PTH(1-34) peptide were found to be important determinants in the induction of bone tumours in rats [34]. Therefore, it is critical to find the right dose and duration of PTHrP(1-36) treatment to balance the positive effects of $\mathrm{PTHrP}$ on the beta cell and its potential negative systemic effects.

While a number of growth factors, signalling and cell cycle molecules have the capacity to enhance rodent beta cell proliferation when expressed transgenically in the beta cell in vivo [35-37], only very few have this effect when administered systemically and acutely in vivo in nondiabetic rodents. In this regard, glucagon-like polypeptide-1 (GLP-1) and its analogues, as well as prolactin constitute two peptide families that induce rodent beta cell proliferation in vivo either when injected or infused continuously [38-40]. GLP-1 and its analogues are currently commercially available drugs for the treatment of diabetes [41, 42]. Like GLP-1, PTHrP(1-36) (1) systemically enhances endogenous rodent beta cell proliferation and mass, (2) acts through a seven transmembrane G-protein-coupled receptor activating many signalling pathways including the cyclic AMP pathway [17], (3) is safe to use in humans as demonstrated through clinical trials of its use in the treatment of osteoporosis $[20,21]$ and (4) therefore has the potential to be used in the future treatment of diabetes. Other growth factors such as gastrin, epidermal growth factor and islet neogenesis-associated protein have also been shown to increase beta cell mass when administered systemically in rodents [43-46]. However, these growth factors increase beta cell mass through differentiation of new beta cells from non-beta cells, rather than by enhancing proliferation of pre-existing beta cells, as observed in our study. Therefore, it would be interesting to examine the effects of systemically administering PTHrP (1-36) in combination with one or more of these other growth factors to determine whether we can further augment beta cell mass through activation of differentiation and proliferation of beta cells.

In conclusion, this study clearly shows that the aminoterminal PTHrP(1-36) peptide is capable of enhancing rodent beta cell proliferation and mass in vivo, without negatively affecting beta cell function or survival, when administered acutely and systemically in normal adult mice. Future studies will determine whether this peptide can be used to induce endogenous beta cell regeneration in models of type 1 and type 2 diabetes or obesity. Given that clinical studies are currently ongoing to determine the ideal dose and treatment regimen of this peptide for the treatment of osteoporosis [20, 21], there is a good chance that $\operatorname{PTHrP}(1-36)$ could be a promising and safe therapeutic agent for diabetes. 
Acknowledgements This work was supported by grants from the National Institutes of Health (DK078060 and DK072264) and the Juvenile Diabetes Research Foundation (1-2008-46) to R.C. Vasavada. We are grateful to L. Alonso, N. Taesch, I. Cozar-Castellano, S. Velazquez-Garcia and S. Ernst for sharing their expertise and for their critical input. Thanks also to N. Vasavada for his assistance with the statistical analysis, and to C. Chin, D. Sipula, T. Rosa and S. Valle for superb technical assistance.

Contribution statement Each of the co-authors contributed to the conception and design, analysis and interpretation of data, and drafting and/or revision of the manuscript, as well as approving the final version to be published.

Duality of interest A.F. Stewart is a member of Osteotrophin LLC. The other authors declare that there is no duality of interest associated with this manuscript.

\section{References}

1. Dor Y, Brown J, Martinez OI, Melton DA (2004) Adult pancreatic beta-cells are formed by self-duplication rather than stem-cell differentiation. Nature 429:41-46

2. Nir T, Melton DA, Dor Y (2007) Recovery from diabetes in mice by beta cell regeneration. J Clin Invest 117:2553-2561

3. Teta M, Rankin MM, Long SY, Stein GM, Kushner JA (2007) Growth and regeneration of adult beta cells does not involve specialized progenitors. Dev Cell 12:817-826

4. Meier JJ, Butler AE, Saisho Y et al (2008) Beta-cell replication is the primary mechanism subserving the postnatal expansion of beta-cell mass in humans. Diabetes 57:1584-1594

5. Efrat S (2008) Ex-vivo expansion of adult human pancreatic betacells. Rev Diabet Stud 5:116-122

6. Philbrick WM, Wysolmerski JJ, Galbraith S et al (1996) Defining the roles of parathyroid hormone-related protein in normal physiology. Physiol Rev 76:127-173

7. Karaplis AC, Luz A, Glowacki J et al (1994) Lethal skeletal dysplasia from targeted disruption of the parathyroid hormonerelated peptide gene. Genes Dev 8:277-289

8. Jobert AS, Zhang P, Couvineau A et al (1998) Absence of functional receptors for parathyroid hormone and parathyroid hormone related peptide in Blomstrand chondrodysplasia. J Clin Invest 102:34-40

9. Qian J, Colbert MC, Witte D et al (2003) Midgestational lethality in mice lacking the parathyroid hormone (PTH)/PTH-related peptide receptor is associated with abrupt cardiomyocyte death. Endocrinology 144:1053-1061

10. Drucker DJ, Asa SL, Henderson J, Goltzman D (1989) The parathyroid hormone-like peptide gene is expressed in the normal and neoplastic human endocrine pancreas. Mol Endocrinol 3:1589-1595

11. Asa SL, Henderson J, Goltzman D, Drucker DJ (1990) Parathyroid hormone-like peptide in normal and neoplastic human endocrine tissues. J Clin Endocrinol Metab 71:1112-1118

12. Fujinaka Y, Sipula D, Garcia-Ocaña A, Vasavada RC (2004) Characterization of mice doubly transgenic for parathyroid hormone-related protein and murine placental lactogen: a novel role for placental lactogen in pancreatic beta cell survival. Diabetes 53:3120-3130

13. Guthalu NK, Joshi-Gokhale S, Harb G et al (2010) Parathyroid hormone-related protein (PTHrP) enhances human $\beta$-cell proliferation and function with simultaneous induction of cyclin- dependent-kinase 2 (cdk2) and CyclinE expression. Diabetes 59:3131-3138

14. Sawada Y, Kameya T, Aizama T, Izumi T, Takeuchi T (2000) Proprotein-processing endoprotease furin and its substrate parathyroid hormone-related protein are coexpressed in insulinoma cells. Endocr Pathol 11:31-39

15. Vasavada RC, Wang L, Fujinaka Y et al (2007) Protein kinase C- $\zeta$ markedly enhances $\beta$-cell proliferation: an essential role in growth factor-mediated $\beta$-cell mitogenesis. Diabetes 56:2732-2743

16. Villanueva-Penacarrillo ML, Cancelas J, de Miguel F et al (1999) Parathyroid hormone-related peptide stimulates DNA synthesis and insulin secretion in pancreatic islets. J Endocrinol 163:403408

17. Zhang B, Hosaka M, Sawada Y et al (2003) Parathyroid hormonerelated protein induces insulin expression through activation of MAP kinase-specific phosphatase-1 that dephosphorylates c-Jun $\mathrm{NH}(2)$-terminal kinase in pancreatic beta-cells. Diabetes 52:2720 2730

18. Vasavada RC, Cavaliere C, D'Ercole AJ et al (1996) Overexpression of parathyroid hormone-related protein in the pancreatic islets of transgenic mice causes islet hyperplasia, hyperinsulinemia, and hypoglycemia. J Biol Chem 271:12001208

19. Porter SE, Sorenson RL, Dann P, Garcia-Ocana A, Stewart AF, Vasavada RC (1998) Progressive pancreatic islet hyperplasia in the islet-targeted, parathyroid hormone-related protein-overexpressing mouse. Endocrinology 139:3743-3751

20. Horwitz MJ, Tedesco MB, Gundberg C, Garcia-Ocana A, Stewart AF (2003) Short-term, high-dose parathyroid hormone-related protein as a skeletal anabolic agent for the treatment of postmenopausal osteoporosis. J Clin Endocrinol Metab 88:569575

21. Horwitz MJ, Tedesco MB, Garcia-Ocaña A et al (2010) Parathyroid hormone-related protein for the treatment of postmenopausal osteoporosis: defining the maximal tolerable dose. J Clin Endocrinol Metab 95:1279-1287

22. Bellido T, Ali AA, Plotkin LI et al (2003) Proteasomal degradation of Runx2 shortens parathyroid hormone-induced anti-apoptotic signaling in osteoblasts. A putative explanation for why intermittent administration is needed for bone anabolism. J Biol Chem 278:50259-50272

23. Rihani-Bisharat S, Maor G, Lewinson D (1998) In vivo anabolic effects of parathyroid hormone (PTH) 28-48 and N-terminal fragments of PTH and PTH-related protein on neonatal mouse bones. Endocrinology 139:974-981

24. Fiaschi-Taesch N, Sicari BM, Ubriani K et al (2006) Cellular mechanism through which parathyroid hormone-related protein induces proliferation in arterial smooth muscle cells: definition of an arterial smooth muscle PTHrP/p27kip1 pathway. Circ Res 99:933-942

25. MacLean HE, Guo J, Knight MC, Zhang P, Cobrinik D, Kronenberg HM (2004) The cyclin-dependent kinase inhibitor p57(Kip2) mediates proliferative actions of PTHrP in chondrocytes. J Clin Invest 113:1334-1343

26. Fiaschi-Taesch N, Sicari B, Ubriani K, Cozar-Castellano I, Takane KK, Stewart AF (2009) Mutant parathyroid hormone-related protein, devoid of the nuclear localization signal, markedly inhibits arterial smooth muscle cell cycle and neointima formation by coordinate up-regulation of p15Ink $4 \mathrm{~b}$ and p27kip1. Endocrinology 150:1429-1439

27. Datta NS, Pettway GJ, Chen C, Koh AJ, McCauley LK (2007) Cyclin D1 as a target for the proliferative effects of PTH and PTHrP in early osteoblastic cells. J Bone Miner Res 22:951-964

28. Beier F, Ali Z, Mok D et al (2001) TGFbeta and PTHrP control chondrocyte proliferation by activating cyclin D1 expression. Mol Biol Cell 12:3852-3863 
29. Miao D, Su H, He B et al (2008) Severe growth retardation and early lethality in mice lacking the nuclear localization sequence and C-terminus of PTH-related protein. Proc Natl Acad Sci USA 105:20309-20314

30. Guo J, Liu BY, Bringhurst FR (1997) Mechanisms of homologous and heterologous desensitization of $\mathrm{PTH} / \mathrm{PTHrP}$ receptor signaling in LLC-PK1 cells. Am J Physiol 273:E383-E393

31. Takasu H, Gardella TJ, Luck MD, Potts JT Jr, Bringhurst FR (1999) Amino-terminal modifications of human parathyroid hormone $(\mathrm{PTH})$ selectively alter phospholipase $\mathrm{C}$ signaling via the type 1 PTH receptor: implications for design of signal-specific PTH ligands. Biochemistry 38:13453-13460

32. Frolik CA, Black EC, Cain RL et al (2003) Anabolic and catabolic bone effects of human parathyroid hormone (1-34) are predicted by duration of hormone exposure. Bone 33:372379

33. Stewart AF, Cain RL, Burr DB, Jacob D, Turner CH, Hock JM (2000) Six-month daily administration of parathyroid hormone and parathyroid hormone-related protein peptides to adult ovariectomized rats markedly enhances bone mass and biomechanical properties: a comparison of human parathyroid hormone 1-34, parathyroid hormone-related protein 1-36, and SDZ-parathyroid hormone 893. J Bone Miner Res 15:1517-1525

34. Vahle JL, Long GG, Sandusky G, Westmore M, Ma YL, Sato M (2004) Bone neoplasms in F344 rats given teriparatide [rhPTH(134)] are dependent on duration of treatment and dose. Toxicol Pathol 32:426-438

35. Vasavada RC, Gonzalez-Pertusa JA, Fujinaka Y, Fiaschi-Taesch N, Cozar-Castellano I, Garcia-Ocaña A (2006) Growth factors and beta cell replication. Int J Biochem Cell Biol 38:931-950

36. Bernal-Mizrachi E, Wen W, Stahlhut S, Welling CM, Permutt MA (2001) Islet beta cell expression of constitutively active Akt1/PKB alpha induces striking hypertrophy, hyperplasia, and hyperinsulinemia. J Clin Invest 108:1631-1638
37. Hino S, Yamaoka T, Yamashita Y, Yamada T, Hata J, Itakura M (2004) In vivo proliferation of differentiated pancreatic islet beta cells in transgenic mice expressing mutated cyclin-dependent kinase 4. Diabetologia 47:1819-1830

38. Bock T, Pakkenberg B, Buschard K (2003) The endocrine pancreas in non-diabetic rats after short-term and long-term treatment with the long-acting GLP-1 derivative NN2211. APMIS 111:1117-1124

39. Doyle ME, McConville P, Theodorakis MJ et al (2005) In vivo biological activity of exendin (1-30). Endocrine 27:1-9

40. Karnik SK, Chen H, McLean GW et al (2007) Menin controls growth of pancreatic beta-cells in pregnant mice and promotes gestational diabetes mellitus. Science 318:806-809

41. Kendall DM, Cuddihy RM, Bergenstal RM (2009) Clinical application of incretin-based therapy: therapeutic potential, patient selection and clinical use. Am J Med 122:S37-S50

42. Waugh N, Cummins E, Royle P et al (2010) Newer agents for blood glucose control in type 2 diabetes: systematic review and economic evaluation. Health Tech Assess 14:1-248

43. Rooman I, Lardon J, Bouwens L (2002) Gastrin stimulates beta-cell neogenesis and increases islet mass from transdifferentiated but not from normal exocrine pancreas tissue. Diabetes 51:686-690

44. Rooman I, Bouwens L (2004) Combined gastrin and epidermal growth factor treatment induces islet regeneration and restores normoglycaemia in C57B16/J mice treated with alloxan. Diabetologia 47:259-265

45. Suarez-Pinzon WL, Lakey JR, Brand SJ, Rabinovitch A (2005) Combination therapy with epidermal growth factor and gastrin induces neogenesis of human islet $\beta$-cells from pancreatic duct cells and an increase in functional $\beta$-cell mass. J Clin Endocrinol Metab 90:3401-3409

46. Rosenberg L, Lipsett M, Yoon JW et al (2004) A pentadecapeptide fragment of islet neogenesis-associated protein increases beta-cell mass and reverses diabetes in C57BL/6J mice. Ann Surg 240:875-884 